\title{
Selection of modalities, prescription, and technical issues in children on peritoneal dialysis
}

\author{
Enrico Verrina • Valeria Cappelli • Francesco Perfumo
}

Received: 28 December 2007 / Revised: 31 March 2008 / Accepted: 31 March 2008 / Published online: 3 June 2008

(C) IPNA 2008

\begin{abstract}
Peritoneal dialysis (PD) is widely employed as a dialytic therapy for uraemic children, especially in its automated form (APD), that is associated with less burden of care on patient and family than continuous ambulatory PD. Since APD offers a wide range of treatment options, based on intermittent and continuous regimens, prescription can be individualized according to patient's age, body size, residual renal function, nutritional intake, and growthrelated metabolic needs. Transport capacity of the peritoneal membrane of each individual patient should be assessed, and regularly monitored, by means of standardized peritoneal function tests validated in pediatric patients. To ensure maximum recruitment of peritoneal exchange area, fill volume should be scaled to body surface area and adapted to each patient, according to clinical tolerance and intraperitoneal pressure. PD solutions should be employed according to their biocompatibility and potential ultrafiltration capacity; new pH-neutral, glucose-free solutions can be used in an integrated way in separate dwells, or by appropriately mixing during the same dialytic session. Kinetic modelling software programs may help in the tailoring of PD prescription to individual patients' characteristics and needs. Owing to advances in the technology of new APD machines, greater programming flexibility, memorized delivery control, and tele-dialysis are currently possible.
\end{abstract}

Keywords Peritoneal dialysis · Children · Automated peritoneal dialysis $\cdot$ Peritoneal membrane function .

Peritoneal dialysis solutions $\cdot$ Peritoneal dialysis prescription

E. Verrina $(\bowtie) \cdot$ V. Cappelli $\cdot$ F. Perfumo

Dialysis Unit, Nephrology and Dialysis Division,

Giannina Gaslini Institute,

Largo G. Gaslini, 5,

16148 Genoa, Italy

e-mail: enricoverrina@ospedale-gaslini.ge.it

\section{Introduction}

Chronic peritoneal dialysis (CPD) currently represents the dialysis treatment modality most commonly prescribed for pediatric patients with end-stage renal disease throughout much of the world, and the preference for CPD over haemodialysis is most pronounced among infants and young children 0 to 5 years of age [1-3].

In this study we addressed the issues of CPD modality selection and prescription, including some technical aspects of the modalities; for reason of space, an effort has been made to summarize accurately current knowledge specific to these issues, but readers are encouraged to consult references cited throughout the paper for more details on specific topics.

Selection of peritoneal dialysis modality The aim of the process of CPD modality selection and prescription is to tailor the treatment schedule to the needs of each individual patient, according to a series of parameters such as the patient's age, body size, associated non-renal diseases, residual renal function (RRF), clinical conditions, blood pressure, nutritional status, and transport characteristics of the peritoneal membrane (PM). At the same time, potential negative effects of CPD treatment on the patient's metabolism and on PM viability should be taken into account. Finally, the burden of CPD treatment should be compatible with a satisfactory level of psychological and social rehabilitation of the patient and of his/her family. During the past $10-15$ years, several technical improvements in materials and devices for peritoneal dialysis (PD), the development of more biocompatible PD solutions, and the employment of computer technology, have provided dialysis staff with valuable tools to improve the efficacy and tolerability of CPD treatment and also to check that the treatment dose has been delivered. 
Since the selection of the most proper CPD modality, as well as the prescription of the optimal treatment schedule, should be based on an accurate assessment of the PM transport characteristics of individual patients, the issue of PM function tests will be addressed first, followed by a brief description of conventional and new PD solutions. Then, CPD treatment methods and regimens will be considered, together with the prescription tools that are currently available.

\section{Peritoneal membrane function tests}

Peritoneal solute and fluid transport may vary considerably from patient to patient and in the same patient during different phases of CPD treatment, as a consequence of the recurrence and/or severity of peritonitis episodes or of the exposure of the PM to CPD solutions and materials. Therefore, PM transport characteristics should be assessed at the beginning of CPD (usually a month after the patient has started peritoneal dialysis) and then monitored every 6 12 months and during recurrent or particularly severe peritonitis or any other clinical event that may cause changes in transport capacity [4, 5].

The application of PM function tests to paediatric patients has long been hampered by a lack of standardization of dialysis mechanics during the test. Appropriate scaling for body size plays a central role for this standardization and for the calculation of membrane function parameters. While in infants the peritoneal surface area per unit body weight (BW) is twice that of adults, the relationship between body surface area (BSA) and PM surface area is constant and age independent. In early pediatric transport studies, standardization of exchange volumes by BW led to a false perception of differences in peritoneal permeability between children and adults, with an enhanced transport function in the youngest patients that was due to faster solute equilibration associated with the use of relatively small dwell volumes [6]. On the contrary, scaling the exchange volume by BSA maintains the relationship between dialysate volume and PM surface area across populations, and makes comparison of peritoneal transport properties between patients of different body sizes possible [7, 8]. An exchange volume of $1,100 \mathrm{ml} / \mathrm{m}^{2} \mathrm{BSA}$ approximates the standard BSA-based volume of 2,000 ml/ $1.73 \mathrm{~m}^{2}$ applied to adult patients.

Measurement of mass transfer area coefficient Diffusive permeability of the peritoneal membrane can be expressed by means of the mass transfer area coefficient (MTAC), which describes the maximum clearance theoretically achievable at a constantly maximum gradient for diffusion (i.e. when dialysate solute concentration is zero) and is independent of dialysate glucose concentration. MTAC can be calculated with the help of computer technology, which can give reliable results also in pediatric patients [9]. Comparison of MTAC values obtained in patients of different ages is possible if exchange volume has been standardized to BSA [9, 10]. However, relatively greater solute transport capacity has been reported in infants, as a consequence of higher peritoneal permeability or larger effective surface area of the peritoneal membrane [10].

The peritoneal equilibration test This test remains the most commonly employed means of characterizing PM transport capacity in adults as well as in children [10-13]. Urea and creatinine dialysate-to-plasma $(\mathrm{D} / \mathrm{P})$ ratios and dialysate glucose concentration to initial dialysate glucose concentration at time $0(\mathrm{D} / \mathrm{D} 0)$, calculated at $2 \mathrm{~h}$ and $4 \mathrm{~h}$ of a standard peritoneal equilibration test (PET) conducted with a $1,100 \mathrm{ml} / \mathrm{m}^{2}$ dwell volume of a $2.5 \%$ dextrose PD solution, can be compared to the results from a large paediatric study in which the same PET procedure was adopted [10]. Thus, patients will be characterized as having high, high average, low average or low, solute transport (Table 1). Similarly to what has been reported in adult patients, the high transporter status may be associated with poor treatment outcome and has been identified as a significant risk factor for inadequate weight control, poor statural growth [14], and low-turnover bone disease [15].

The PET can be also performed with a $4.25 \%$ dextrose PD solution to obtain more accurate information on ultrafiltration (UF) capacity and sodium sieving [16].

Recently, Warady and Jennings reported that the PET results obtained at $2 \mathrm{~h}$ and $4 \mathrm{~h}$, based on either creatinine or glucose transport in 20 children who had been on PD for 7 months or less, provided identical characterization of peritoneal membrane transport capacity for the same solute [17]. Therefore, the authors proposed the use in paediatric patients of a simplified, $2 \mathrm{~h}$ PET procedure, the so-called short PET, as already described in adult patients by Twardowski et al. in the original publication of the PET [11].

Table 1 Peritoneal equilibration test results for urea, creatinine and glucose. The four categories of peritoneal transport are bordered by the maximum, mean +1 standard deviation $(\mathrm{SD})$, mean, mean $-1 \mathrm{SD}$, and minimum values for the study population. $D / P$ dialysate-toplasma ratio, $D / D 0$ dialysate glucose to initial dialysate glucose concentration ratio. Data adapted from [10] and used with permission

\begin{tabular}{llll}
\hline $\begin{array}{l}\text { Category of } \\
\text { peritoneal transport }\end{array}$ & $\mathrm{D} / \mathrm{P}$ urea $^{\mathrm{a}}$ & $\begin{array}{l}\mathrm{D} / \mathrm{P} \\
\text { creatinine }^{\mathrm{a}}\end{array}$ & $\begin{array}{l}\mathrm{D} / \mathrm{D} 0 \\
\text { glucose }^{\mathrm{a}}\end{array}$ \\
\hline High & $0.91-0.94$ & $0.77-0.88$ & $0.12-0.21$ \\
High average & $0.82-0.90$ & $0.64-0.76$ & $0.22-0.32$ \\
Low average & $0.74-0.81$ & $0.51-0.63$ & $0.33-0.42$ \\
Low & $0.54-0.73$ & $0.37-0.50$ & $0.43-0.55$ \\
\hline
\end{tabular}

${ }^{\mathrm{a}}$ At a $4 \mathrm{~h}$ dwell of an exchange performed with $1,100 \mathrm{ml} / \mathrm{m}^{2} \mathrm{BSA}$ of a $2.5 \%$ dextrose solution 
Since the short PET is more convenient for patients, families, and nursing staff and is associated with cost savings, the adoption of this procedure may help in the evaluation of transport characteristics of the peritoneal membrane on a more routine basis among paediatric PD centres. However, further study with a larger patient cohort is required to confirm the accuracy of the short PET in the characterization of membrane transport capacity in this setting [18].

Two other tests for peritoneal membrane function that have given reliable results in adults as well as in paediatric patients, but are less frequently employed than the PET in the clinical setting, are the so-called standard permeability analysis and the personal dialysis capacity test.

Standard permeability analysis In this test, polydisperse dextran-70 is added to the PD solution employed in the PET so that simultaneous measurement is obtained of transcapillary ultrafiltration (UF), marker clearance rates, and intraperitoneal volume (IPV). Standard permeability analysis (SPA) conducted with a test IPV of $1,200 \mathrm{ml} / \mathrm{m}^{2}$ and a $1.36 \%$ or $3.86 \%$ glucose PD solution gave comparable results in adult and pediatric patients $[19,20]$.

Personal dialysis capacity test This test [21] is based on the three-pore model of solute and fluid transport across the peritoneum, which is characterized as a heteroporous threepore membrane with few (approximately $1-2 \%$ ) waterexclusive ultra-small pores, called aquaporins (radius 0.2$0.4 \mathrm{~nm}$ ), a small percentage (approximately $5 \%$ ) of large pores (radius 20-30 nm), and a majority (approximately 90-95\%) of small pores (radius 4-6 nm). Small solute transport occurs primarily by diffusion across the small pores, while proteins and other macromolecules are driven by convection across the large pores. Fluid transport is determined by crystalloid and colloid osmotic pressures and can occur across all three pathways. By personal dialysis capacity (PDC) test the following three parameters can be calculated: (1) the effective peritoneal surface area, or unrestricted pore area over diffusion distance $\left(\mathrm{A}_{0 /} \Delta \mathrm{X}\right)$, corresponding to the diffusion capacity for solutes; (2) absorption, i.e. the final rate of fluid reabsorption from the abdominal cavity, and (3) the large-pore volume flow, which represents the rate of protein-rich fluid passing through the large pores from the blood to the dialysate. PDC protocol includes five exchanges to be performed in $24 \mathrm{~h}$, using different dwell times and two glucose solutions for patients on continuous ambulatory peritoneal dialysis (CAPD); a simplified protocol for patients on APD is also available [22]. The PDC test has been successfully employed in children to model individual peritoneal membrane function [22]. In one paediatric study, $\mathrm{D} / \mathrm{P}$ or D/D0 ratios derived from PET analysis were used to estimate $\mathrm{A}_{0 /} \Delta \mathrm{X}$ with a specific computer program [23].

\section{Peritoneal dialysis solutions}

Several types of PD solutions have been made commercially available that achieve satisfactory removal of fluid and waste products and maintain acid-base and calcium balance and electrolyte homoeostasis. The increasing knowledge of the harmful effects of prolonged exposure of the peritoneal membrane to standard PD solutions with high glucose and lactate concentration, low $\mathrm{pH}$, high osmolarity, and high level of glucose degradation products (GDPs) has led to the development of more biocompatible, second-generation PD solutions. Studies done recently support the hypothesis that peritoneal membrane hypervascularization and fibrosis observed during long-term $\mathrm{PD}$ are correlated to acute and chronic toxicity of conventional PD fluids. Furthermore, progressive decline of residual renal function, which is considered a major determinant of PD treatment outcome, can be exacerbated by the metabolic and cardiovascular burden related to glucose load, GDPs accumulation, and oxidative stress [24-26].

Glucose remains the most widely employed osmotic agent in the clinical setting. The crystalloid osmotic effect of glucose, which is exerted through the aquaporins, can be effectively enhanced by increasing its concentration in the PD fluid. The rapid and variable absorption rate of glucose from the peritoneal fluid dissipates the osmotic gradient and makes it unsuitable to obtain adequate UF during long dwells and in patients with high peritoneal transport rates. Glucose absorption may worsen the anorexia, hyperglycaemia, dyslipidaemia, and insulin resistance as well as the increased oxidative stress that are often associated with the uraemic syndrome. Moreover, long-term exposure to the elevated glucose concentration of PD fluids contributes to structural (submesothelial thickening and fibrosis, and vascular proliferation) and functional (UF failure) changes in the peritoneal membrane. The main mechanisms by which glucose-based PD fluids induce these deleterious effects on peritoneum are represented by:

- hyperosmolar stress

- the presence of highly reactive glucose GDPs that impair mesothelial cell function and modulate cytokine generation

- glycation of structural proteins and formation of advanced glycation end products (AGEs)

- effects on peritoneal cell metabolism via the polyol pathway, protein kinase activation and gene induction [26-28].

Reduced formation of GDPs has been obtained by the separation of glucose from other contents in a doublechamber bag system that allows glucose sterilization at a lower $\mathrm{pH}$ than is possible in single-chamber bags $[28,29]$. Significant reduction of plasma AGE levels has been 
reported in paediatric patients by administration of lowGDP PD solutions [30].

In summary, glucose is effective in UF induction along short dwells, but the lowest glucose concentration of PD solution should be used in daily practice while still being compatible with the patient's clinical needs [31].

Icodextrin As an alternative to glucose-based PD solutions during prolonged dwells, PD solutions containing a polymer of glucose with an average molecular weight (MW) of 16,200 Da (icodextrin) have been extensively studied and applied to adult PD patients. The colloid osmotic effect of a $7.5 \%$ icodextrin solution that is exerted through the small pore was able to obtain sustained, net UF during a $14 \mathrm{~h}$ dwell [32]. Studies in paediatric patients showed the same UF profile as in adults, an increase in solute removal, and rare, mild side effects (skin rash) [3335]. By comparing the results of two $4 \mathrm{~h}$ PETs, performed on nine paediatric patients and using $3.86 \%$ glucose and $7.5 \%$ icodextrin as a test solution, Rusthoven et al. [36] found that the two solutions had different effects on the change in intraperitoneal pressure (IPP); during the PET performed with a $3.86 \%$ glucose solution, the increase in IPP was positively correlated with transcapillary UF and inversely correlated with the patients' BSA, while, by using an icodextrin solution, they found that the IPP hardly increased during the $4 \mathrm{~h}$ dwell and no correlation was found with fluid kinetics or patient BSA.

Since the colloid osmotic effect exerted by icodextrin does not induce sodium sieving, sodium removal is usually higher than that obtained with glucose-based solutions [37].

In children icodextrin absorption was reported to be $45 \%$ over $14 \mathrm{~h}$ [34]. Icodextrin is metabolized by amylase to maltose and a number of oligosaccharides, whose serum levels usually reach a steady state within 2 weeks from the start of treatment and go back to zero 2 weeks after discontinuation of the use of icodextrin solution [33]. Sterile peritonitis was reported in some patients treated with icodextrin and was caused by peptidoglycan contamination of the dialysate by thermophilic, acidophilic bacteria [38].

In vitro and ex vivo studies have shown that icodextrin solution is more biocompatible with the peritoneal membrane than is glucose-based solutions, possibly due to its iso-osmolar property, lack of glucose, and lower GDP content [39]. However, it has been recently reported that icodextrin may also inhibit the normal process of mesothelial cell repopulation and induce repair by means of connective tissue formation [40].

In summary, icodextrin solution is indicated for: long night-time dwell in continuous ambulatory PD (CAPD); long daytime dwell in continuous cycling PD (CCPD); patients with type I UF failure or transient UF failure associated with peritonitis. Icodextrin is currently licensed for use in not more than one dwell per day, out of concern for the potential side effects of its low molecular weight metabolites.

Combination of different solutions With the aim of optimizing fluid removal and reducing glucose exposure, a combination solution of glucose and icodextrin has been employed with encouraging results during a daytime dwell in adult patients. [41, 42]. Studies on the use of bimodal PD solutions in paediatric patients should be encouraged.

The concept of prescribing a mixture of dialysis fluids in order to take the maximum advantage of each component has been applied to the use of amino acid (AA) PD solutions. In children on CAPD the effect on nutritional status of using an AA solution in a long dwell was anecdotal. Increases in blood urea nitrogen and worsening of acidosis have been observed [43]. On the other hand, combined intraperitoneal infusion of AA and glucose during nocturnal APD sessions promoted the utilization of AA for protein synthesis [44]. This schedule was reported to improve anthropometric parameters in children on APD [45] and to influence positively muscle protein turnover in adult patients [46].

A $1.1 \%$ AA solution is as osmotically efficient as a $1.36 \%$ glucose solution is; moreover, a certain increase in solute removal and UF may be expected, since AAs tend to induce peritoneal vasodilatation and, hence, recruitment of microvascular surface area to a greater extent than glucose does [47].

In summary, the use of AA solution in children on APD can be indicated in order to improve treatment biocompatibility and to supply AA in malnourished patients. However, in these patients enteral nutrition should be used whenever possible to improve nutritional status [31].

Bicarbonate-based PD solutions The use of lactate-buffered $\mathrm{PD}$ solutions with low $\mathrm{pH}$ is associated with a series of well-known clinical, metabolic and biocompatibility drawbacks (Table 2). Neutral pH (7.0-7.6) PD solutions containing, $34 \mathrm{mmol} / \mathrm{l}$ of bicarbonate, or $25 \mathrm{mmol} / \mathrm{l}$ of bicarbonate plus $15 \mathrm{mmol} / \mathrm{l}$ of lactate, are commercially available in multi-compartment bag systems [31]. Adult and paediatric studies have shown that the use of these bicarbonate-buffered PD solutions is associated with better biocompatibility, more effective correction of acidosis, and lower incidence of infusion pain than that of conventional lactate-buffered solutions [48-50]. Schmitt et al. [51] found that peritoneal mass transfer kinetics were similar with bicarbonate and lactate for water and most solutes, except for slightly lower phosphate and creatinine transport rates, at $1 \mathrm{~h}$ dwell time with bicarbonate solutions. These more physiological PD fluids have been shown to prevent hyperperfusion and to reduce the loss of proteins into 
Table 2 Effects of toxins on membrane integrity (left side of table) and clinical and metabolic drawbacks (right side of table) that may be correlated with the use of lactate-buffered PD solutions

\begin{tabular}{ll}
\hline $\begin{array}{l}\text { Effects of toxins on } \\
\text { membrane integrity }\end{array}$ & $\begin{array}{l}\text { Clinical and metabolic } \\
\text { drawbacks }\end{array}$ \\
\hline $\begin{array}{l}\text { Local release of cytokines } \\
\text { and growth factors: }\end{array}$ & $\begin{array}{l}\text { Need of lactate conversion } \\
\text { to bicarbonate in the liver }\end{array}$ \\
$\rightarrow$ inflammatory state & \\
$\rightarrow$ fibrogenic processes & neo-angiogenesis \\
$\rightarrow$ peritoneal fibrosis & Loss of bicarbonate due to its \\
Impairment of & back-diffusion into the dialysate \\
$\rightarrow$ mesothelial cell integrity & Abdominal pain during the \\
$\rightarrow$ peritoneal macrophage & inflow of dialysate \\
function & \\
$\rightarrow$ intraperitoneal host defence & \\
$\rightarrow$ membrane permeability &
\end{tabular}

dialysate; their use has been associated with lower intraperitoneal pressure, reflecting enhanced tolerance of fill volume, but also with a reduction of the unrestricted area over diffusion distance and of the vascular exchange area [50].

In summary, bicarbonate seems to be the most suitable buffer for PD solutions to be used in paediatric patients who frequently undergo the short dwell cycles of night APD schedules [31]. However, long term clinical trials would be needed to confirm the impact of bicarbonatebuffered solutions on peritoneal membrane viability.

Calcium Commercially available PD solutions contain: (1) $1.75 \mathrm{mmol} / 1$ of calcium; since ionized calcium in these solutions is higher than the ionized calcium level normally present in blood, diffusion of calcium from dialysate to blood would lead to a positive calcium balance; (2) $1.25 \mathrm{mmol} / \mathrm{l}$; these solutions are frequently employed with the goal of reducing the risk of hypercalcaemia, especially in children receiving calcium carbonate or calcium acetate as phosphate binders and being treated with vitamin D analogues [31]. Attention should be paid to avoid hypercalcaemia and a high calcium $\mathrm{x}$ phosphate product for the potential risk of inducing vascular and soft tissue calcification. Use of non-calcium-containing phosphate binders would be indicated in these cases.

\section{Prescription for PD regimen}

PD prescription should be tailored on the basis of the child's age, body size, residual renal function (RRF), nutritional intake, and transport capacity of the peritoneal membrane. Moreover, the prescribed PD schedule should be compatible with the psychological and social needs of the patient and family. Technical parameters that should be primarily considered in the prescriptive process are $[4,13$, 52]:

(1) status of peritoneal membrane transport, evaluated by means of validated functional tests

(2) PD solution, selected according to biocompatibility and potential UF capacity

(3) fill volume, tailored to the patient's needs and tolerance

(4) exchange dwell time, optimized for small and middlesized molecule removal and UF

Prescription of fill volume Scaling IPV by patient BSA has become a standard in paediatric PD prescription $[4,13,52]$. IPV and the patient's posture dynamically affect the recruitment of an effective peritoneal membrane area for dialytic exchange, which corresponds to the unrestricted pore area over diffusion distance $\left(\mathrm{A}_{0} / \Delta \mathrm{X}\right)$ as determined with the three-pore model $[21,23]$. Raising IPV from $800 \mathrm{ml} / \mathrm{m}^{2}$ BSA to $1,400 \mathrm{ml} / \mathrm{m}^{2}$ BSA leads to maximization of peritoneal vascular surface area [23]. On the other hand, excessive IPV may cause patients discomfort, pain, dyspnoea, hydrothorax, hernia, gastroesophageal reflux, and loss of UF due to increased lymphatic drainage. Hydrostatic intraperitoneal pressure (IPP) is a reproducible patient-characteristic parameter, and its measurement helps to evaluate fill volume tolerance in the individual patient [53]. For a patient in a supine position, fill volume leading to an IPP of $18 \mathrm{~cm} \mathrm{H}_{2} \mathrm{O}$ is considered to be the maximum tolerable IPV, above which abdominal pain and a decrease in respiratory vital capacity may occur [52]. An IPV of $1,400 \mathrm{ml} / \mathrm{m}^{2}$ BSA seems to be the optimum for ensuring optimal recruitment of vascular pore area in children; however, this should be considered as a maximum limit, the safety of which has not been validated in children. In clinical practice, fill volume can be increased in steps up to the limit of $1,400 \mathrm{ml} / \mathrm{m}^{2} \mathrm{BSA}$ for a night exchange, while the patient is lying down, according to clinical tolerance and IPP measurement [52].

Prescription of dwell time Dwell duration should always be determined according to the individual patient's transport status [4, 13, 52]. Short exchanges lead to satisfactory clearance of small solutes (such as urea) and UF, which can be further enhanced by increasing dialysate glucose concentration. Patients with high rates of transport would benefit from short exchanges, due to dissipation of osmotic gradients by fast glucose absorption. Long exchanges favour the removal of solutes of relatively high molecular weights, such as creatinine and phosphate, but can be associated with 
impaired UF or even with dialysate reabsorption if glucosebased solutions are being used. An icodextrin-based solution is more appropriate for such long dwells [31, 33].

A potentially useful way to individualize dwell duration in paediatric patients on automated PD (APD) according to peritoneal transport capacity is the calculation of the socalled APEX time. In the PET, the APEX time corresponds to the point at which the $\mathrm{D} / \mathrm{P}$ urea and $\mathrm{D} / \mathrm{D} 0$ glucose equilibration curves cross, and should represent the optimal length of APD cycles [54].

The above-mentioned prescription principles should be applied to the delivery of different PD regimens, which will be briefly described $[4,31,55]$.

Continuous ambulatory peritoneal dialysis CPD was originally performed as CAPD, a continuous regimen that allows complete equilibration of small solutes and a certain removal of middle-sized molecules. This PD modality has the undoubted advantage of ease of use and limited cost of the equipment. CAPD is usually effective in children with RRF, but its decline should be closely monitored. According to the guidelines of the European Committee on adequacy of the pediatric PD prescription [4], initial fill volume can be $600-800 \mathrm{ml} / \mathrm{m}^{2}$ during the day and 800 $1,000 \mathrm{ml} / \mathrm{m}^{2}$ overnight, and can then gradually be increased according to the patient's tolerance and IPP measurements. An icodextrin-based solution can be used for the prolonged night-time dwell. As a further step, the number of exchanges can be increased from four to five per day. However, if increasing the number of exchanges to obtain adequate UF and solute removal represents an excessive burden upon the families, a shift of the patient to an APD modality should be considered.

Automated peritoneal dialysis APD represents the PD modality of choice for paediatric patients, at least in countries that have no cost constraints [2,3]. Financial and technical problems still represent a limitation to the use of APD for many units in developing countries.

Reasons for the preference of APD are reported in Table 3. APD offers a wide selection of treatment schedules that has in common the use of automated machines for fluid delivery, currently called 'cyclers', and the high efficiency obtained through short dwell times, high dialysate flows, and large IPV.

Nightly intermittent $P D$ Nightly intermittent peritoneal dialysis (NIPD) consists of a number of short nocturnal cycles, without a daytime dialysate dwell, and is primarily indicated for patients characterized by a high-transport peritoneal membrane, which allows rapid solute equilibration. The main advantages of a dry abdomen during the day
Table 3 Reasons for preference of automated peritoneal dialysis (APD) in paediatric patients (IPP intraperitoneal pressure, $P M$ peritoneal membrane)

Why APD is preferred

Wide range of treatment options

$\rightarrow$ tailoring of APD prescription according to:

- age

- body size

- clinical conditions

- growth-related metabolic needs

- residual renal function

- PM transport status

Large fill volume in the night-time exchanges

$\rightarrow$ recruitment of functional peritoneal surface area

Option of an empty abdomen during the day

- normal IPP (less risk of hernias)

- reduced glucose absorption

- reduced exposure of PM to dialysis fluid

- reduced loss of proteins and amino acids

Psychological and social rehabilitation

$\rightarrow$ reduced impact of treatment on patient/family lifestyle

include normal IPP, and the reduction of glucose absorption, of AA and protein loss, and of membrane exposure to glucose. On the other hand, the absence of a daytime dwell is a limitation for solute clearance (especially for middlesized molecules), and it makes NIPD not suitable for patients with low and low-average peritoneal transport. NIPD is frequently adopted as the first APD regimen for patients with a significant RRF. Then, NIPD prescription can evolve according to clearance and UF requirements, that are mostly dictated by the decline of RRF. NIPD efficiency can be enhanced by increasing dwell volume, total treatment time, and the number of exchanges up to a point beyond which solute clearance and water removal may decrease as the non-dialytic time, corresponding to the fill and drain phases, becomes unacceptably long.

Tidal PD With this modality, an initial infusion of solution into the peritoneal cavity is followed by only partial dialysate drainage; thus, an intra-abdominal volume is always left. Drained tidal volume is replaced with fresh dialysis fluid to restore initial IPV, while the entire dialysate volume is drained at the end of the PD session. The amount of ultrafiltrate expected to be generated during each cycle must be estimated and added to the drain volume, to prevent overfilling of the peritoneal cavity. Continuous contact between dialysate and peritoneal membrane maintains a sustained diffusion of solutes, and the efficiency of the dialysis modality is further increased by reducing inflow and outflow dead times, particularly when high dialysate flow rates are used. Tidal PD is also adopted to avoid repeated cycler alarms of low flow rate in case of catheter malfunction, and to reduce 
pain occurring during the drainage phase. The efficiency of tidal peritoneal dialysis (TPD) is mainly conditioned by total volume of PD fluid delivered and by the individual's peritoneal transport rate. Patients with high transport rates can reach adequate solute clearances with intermittent nightly TPD, while patients with high average transport rates would benefit from one or more daytime dwells [56, 57]. A further increase of TPD efficiency can be attained by adapting tidal volume to the drainage profile of each patient, thus reducing the fill and drain dead times [58]. In fact, the drainage profile of peritoneal fluid is not linear, since a high flow rate is maintained until the so-called breakpoint, when a critical intraperitoneal volume is reached. Then, the flow rate drops, and, during the final, slow-flow portion of the drainage phase, the peritoneal cavity is almost empty and solute clearance is greatly reduced [59]. Since critical intraperitoneal volume is an individual characteristic, tidal volume can be tailored to the drainage profile of each patient, thus reducing idle time and improving the overall efficiency of the system.

Continuous cycling PD In CCPD, a fresh exchange of dialysis solution, ranging in volume from $50 \%$ to $100 \%$ of the fill volume, applied at night, is left in the abdomen at the end of the nocturnal APD session. Daytime exchange dialysate can be drained at bedtime, when the cycler is reconnected, so that the patient's involvement is reduced to one session for preparation of the equipment and connection to cycler, and one short disconnection in the morning. Over a long daytime exchange, complete equilibration of small-solute concentration between plasma and dialysate is often achieved; moreover, middle-sized uraemia toxins are poorly influenced by short cycles of APD and much more dependent on complete saturation of dialysis solution during long dwell exchanges [60]. Phosphate PD clearance is usually insufficient to obtain a satisfactory control of hyperphosphataemia, and there is a continued need for dietary restriction and phosphate binder administration; however, phosphate removal by PD can be improved by increasing dwell volume and by optimizing exchange duration through the calculation of the so-called phosphate purification dwell time (PPT) from a PET [54].

A continuous PD regimen is recommended when RRF becomes negligible, and it is indicated in patients with highaverage rates of peritoneal transport. Icodextrin solution is typically employed for the long daytime exchange [31, 33, 34]. If a further increase in solute clearance and UF is desired, more than one diurnal exchange can be performed, optimizing the length of each dwell according to the patient's peritoneal transport rate and the type of osmotic agent employed (continuous optimal peritoneal dialysis, COPD) [4, 60].

The delivered dialysis dose should be adjusted and monitored in accordance with the 2006 update of the
National Kidney Foundation/Kidney Disease Outcomes Quality Initiative (NKF-KDOQI) clinical practice recommendations for paediatric peritoneal dialysis adequacy (Table 4) [13]. In the absence of definitive results from large randomized controlled studies on the correlation between solute removal and clinical outcome in paediatric patients treated by PD, current clinical opinion supports the recommendation that the target delivered solute clearance should meet or exceed that of the adult standards. In patients with RRF, the contribution of renal and peritoneal clearance can be added for practical reasons. In general, results of the prescribed PD schedule should regularly assessed, taking into account not only numerical targets of small-solute depuration, but also all the parameters involved in the definition of adequacy of dialysis treatment in childhood, such as adequate growth, blood pressure control, and nutritional status; avoidance of hypovolaemia and sodium depletion; adequate psychomotor development $[4,13,14]$.

The use of software programs for APD prescription In the clinical setting, the selection of a personalized PD schedule, among the wide range of treatment options that are available with APD, can be facilitated by kinetic modelling. Mathematical modelling software programs, that have a specific individual peritoneal function test as data entry, have been developed to calculate kinetic parameters, to simulate the results of APD regimens, and rapidly find the best personalized dialysis schedule, thus omitting the conventional 'trial and error' approach [61]. Two of these software programs have been validated in children $[9,22,62]$. The accuracy of these mathematical models in predicting solute removal was good, while UF prediction was less accurate. The limited performance with respect to UF prediction may be related to the inability of kinetic modelling to account for changes in residual dialysate volumes, the marked day-to-day variability of UF, the large variability of daily fluid intake, and the confounding effect of residual diuresis in non-anuric patients [63, 64]. Moreover, mathematical modelling refers to perfect and virtually uneventful APD sessions, with no alarms and no delay in the fill and drain phases; therefore, simulation may, at times, be 'optimistic'. In conclusion, computer-assisted kinetic models are useful tools for selecting the optimal dose of dialysis for a given patient, but direct measurement of actual solute clearances and UF rate remains mandatory.

\section{Technical issues}

Over the past 15 years, CPD has experienced a great and quite fast evolution, which has been mostly linked to the 
Table 4 Solute clearance targets and measurements in children on maintenance peritoneal

Targets and measurements

The minimal delivered dose of total (peritoneal and kidney) small-solute clearance should be a $\mathrm{Kt} / \mathrm{V}_{\text {urea }}$ of at least $1.8 /$ week

Total solute clearance should be measured in a clinically stable patient:

$\rightarrow$ within the first month after dialysis has been initiated

$\rightarrow$ at least once every 6 months thereafter (but in patients with residual renal function $24 \mathrm{~h}$ urine collection for determination of volume and solute clearance should be obtained at a minimum of every 3 months)

$\rightarrow$ more frequently when clinical events are likely to have resulted in decreased clearance or when new/worsening signs or symptoms of uraemia develop

$\rightarrow$ at least 1 month after resolution of an episode of peritonitis

$\rightarrow$ if a patient is not doing well and has no other identifiable cause other than kidney failure

When calculating $\mathrm{Kt} / \mathrm{V}_{\text {urea }}, \mathrm{V}$, or total body water, should be estimated by using gender-specific nomograms based upon equations that include the patient's height and weight [77]

development of safe and simple-to-use connecting devices, more biocompatible solutions, and new automatic machines for PD delivery (cyclers).

The use of an integrated Y set, double-bag system, with a disinfectant-containing cap, and a 'flush before fill' mode, has been associated with a reduction in the incidence of peritonitis episodes due to manual contamination and has contributed to the simplification of PD connecting manoeuvres, thus shortening patient and partner training [55, 65-67].

Modern cyclers for APD are characterized by small size, light weight, and portability, as well as their user-friendly interface, which represent basic requirements for homebased therapy devices $[55,68]$. From a technical point, these machines have a great programming flexibility and are equipped with a cassette specific for the tubing set, and automated devices for its connection with the dialysate bags to minimize the risk of operator error and contamination; online warming of dialysate; gravity-assisted pumps for dialysate infusion and drainage; pressure monitors to assess IPP [68].

APD of paediatric patients is performed through a specific paediatric mode of the cycler, which allows accurate delivery of small dialysate volumes $(60 \mathrm{ml}$ per exchange, with $10 \mathrm{ml}$ increments), with as limited a recirculation as possible, and drainage of peritoneal effluent at a low flow rate without triggering the alarm.

The technology incorporated in the cyclers has also led to the possibility of treatment prescription and events being memorized on an electronic device, thus providing information on the delivered dialysis dose and UF, on patient's compliance to APD prescription, and on peritoneal catheter function. For instance, cyclers can record the drainage profile of each exchange, giving graphs of the pattern of catheter flow, and can detect the breakpoint in each cycle, and accordingly adapt the drain profile. This database of therapy information can be downloaded from the memory card of the cycler during the patient's visits to the dialysis unit, or it can be retrieved via a modem on a regular basis. The telecommunication link between the patient's cycler at home and a computer at the dialysis unit can improve the care of patients living at distance from the dialysis centre, through the early detection of a series of clinical and technical problems [69]. For instance, these might be represented by an imperceptible, but progressive, decrease in UF rate, or by a prolongation of the drainage phase due to a catheter malfunction that is still too small to trigger cycler alarms. Moreover, the awareness of routine data recording and transmission can help the patient to be more confident of treatment control and help the dialysis doctors and nurses to update PD prescription more rapidly. The tele-dialysis system can also be integrated into videoconferencing equipment to conduct tele-consultations [70, 71]. In the only available paediatric report on this kind of tele-care support, the videophone equipment employed still showed technical limitations and was considered to be not cost-effective [72]; therefore, this technology deserves further evaluation in paediatric home PD.

Further advances in cycler technology will include the ability to optimise PD regimens, by using the recorded information on the patient's response to a given treatment to suggest an improved schedule, or even to attempt to improve it automatically. As examples, online detection of UF could serve as information for automatic feed-back on the bedside production of the next cycle PD fluid, which will be individualized with respect to osmotic agent, buffer, calcium, and sodium content $[68,73,74]$.

\section{Conclusions}

In conclusion, issues that may have a major impact on the ability to individualize PD treatment and to preserve the efficacy of the prescribed regimen over time will be briefly recalled (Fig. 1).

An important step in the process of individualizing PD prescription is represented by the characterization of PM 


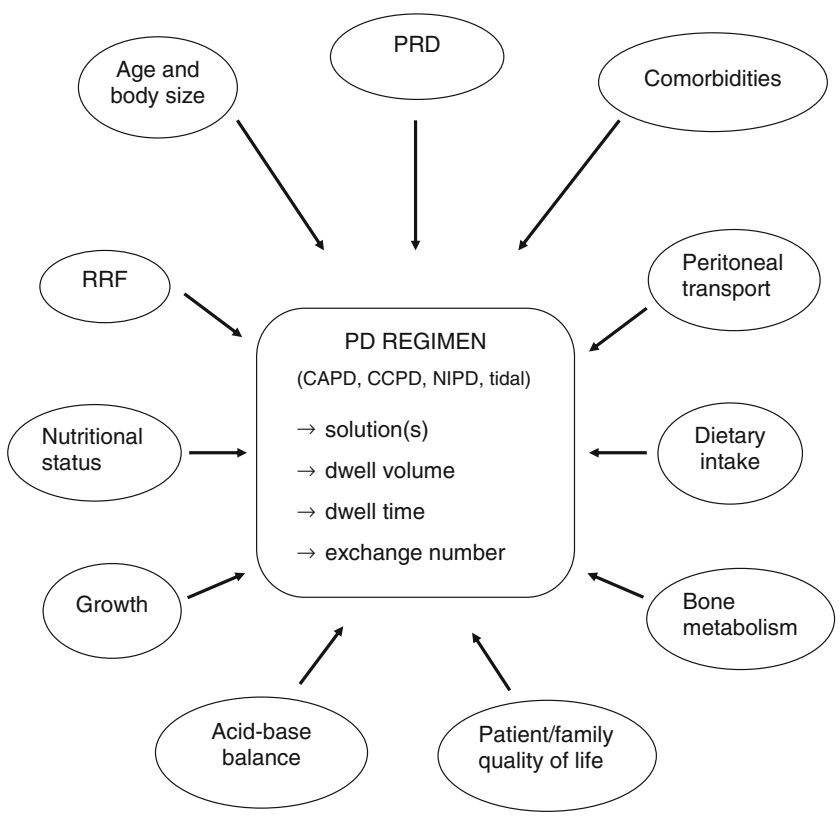

Fig. 1 Factors that should be accurately evaluated for each individual patient in the process of peritoneal dialysis (PD) prescription, and $\mathrm{PD}$ regimen parameters that have to be defined to achieve the final treatment schedule ( $P R D$ primary renal disease, $R R F$ residual renal function)

transport capacity, which should be assessed by means of well standardized functional tests that have been validated in paediatric patients.

Fill volume should be scaled to body surface area and adapted to each patient, according to clinical tolerance and IPP measurement, in order to ensure maximum recruitment of peritoneal exchange area.

Children represent a patient category that would greatly benefit from the use of new, more physiological and biocompatible, PD solutions, especially if one considers their long-term dependence on a functioning peritoneal membrane in case of a kidney transplant failure and the fact that, in APD, frequent short cycles continuously expose the peritoneal membrane to a non physiological and bioincompatible milieu. Combined use of glucose, amino acids, and icodextrin as part of a glucose-sparing APD regimen, together with the adoption of pH-neutral solutions, may represent a strategy that would adequately manage solute removal and UF, while preserving PM integrity over time.

Fluid balance is increasingly recognized as a crucial aspect of the PD patient's treatment, as the efficiency of water and salt removal is associated with patient outcome, especially in anuric patients, and UF failure is an important cause of failure of the technique [75].

Prospective randomized trials of dialysis adequacy and observational studies in adult patients have confirmed that $\mathrm{RRF}$ is a much stronger predictor of patient survival than peritoneal clearance. Therefore, the PD prescription should be aimed to preserve RRF for as long as possible [13, 76], by gradually increasing the dialysis dose in steps, accurately targeting UF rate to maintain the patient's dry body weight, and using the lowest possible dialysate glucose concentration required to achieve the desired UF volume. Prevention of RRF loss also involves the avoidance of nephrotoxic insults (medications, radiocontrast agents, urinary obstruction and infection) and the use of loop diuretics. The potential role of angiotensin-converting enzyme inhibitors and angiotensin-receptor blockers is worth investigating in interventional outcome studies in children on PD. As RRF declines over time, PD prescription should be adjusted in a timely fashion.

The evolution of APD has been closely linked with the advances in the technology incorporated in the new cyclers that have made APD delivery safer and more efficient. Whether tele-dialysis is able to reduce significantly the need for patient hospitalization or the incidence of technique failure in a population of home APD children should be evaluated in large-scale studies.

The ultimate goal of the whole process of PD modality selection and prescription is to identify, and possibly achieve, the optimal PD dose for each individual patient; this can be regarded as the amount of dialysis above which the additional expected benefit does not justify the increase of the burden on patient and family and of financial costs.

\section{Questions}

(Answers appear following the reference list.)

1. On what anthropometric parameter should fill volume prescription be scaled in paediatric patients?
a. Weight
b. Height
c. Body surface area
d. Body mass index

2. What is the $\mathrm{pH}$ of standard, lactate-based $\mathrm{PD}$ solutions?
a. $7.0-7.6$
b) $5.5-6.5$
c. $4.0-4.5$
d. $<4.0$

3. Through which chemical mechanism does icodextrin induce fluid removal?
a. Crystalloid osmosis
b. Diffusion
c. Colloid osmosis
d. Hydrostatic pressure

4. Which of the following solutes is more efficiently removed during short dwells?
a. Creatinine
b. Phosphate 

c. Beta-2-microglobulin
d. Urea

5. In what prescription parameter do nightly intermittent PD and continuous cycling PD mainly differ from one another?
a. Number of night-time exchanges
b. Dry or wet abdomen during the day
c. Tonicity of dialysate
d. Night-time fill volume

\section{References}

1. Hattori S, Yosioka K, Honda M, Ito H (2002) The 1998 report of the Japanese National Registry data on pediatric end-stage renal disease patients. Pediatr Nephrol 17:456-461

2. Verrina E, Edefonti A, Gianoglio B, Rinaldi S, Sorino P, Zacchello G, Lavoratti G, Maringhini S, Pecoraro C, Calevo MG, Turrini Dertenois L, Perfumo F (2004) A multicenter experience on patient and technique survival in children on chronic dialysis. Pediatr Nephrol 19:82-90

3. Fadrowki JJ, Frankenfield D, Amaral S, Brady T, Gorman GH, Warady B, Furth SL, Fivush B, Neu AM (2007) Children on longterm dialysis in the United States: findings from the 2005 ESRD Clinical Performance Measures Project. Am J Kidney Dis 50:958966

4. Fischbach M, Stefanidis CJ, Watson AR (2002) Guidelines by an ad hoc European committee on adequacy of the pediatric peritoneal dialysis prescription. Nephrol Dial Transplant 17:380 385

5. Morgestern B (2004) Peritoneal dialysis and prescription monitoring. In: Warady BA, Schaefer FS, Fine RN, Alexander SR (eds) Pediatric dialysis. Kluwer Academic Publishers, Dordrecht, p 147 $-161$

6. Geary DF, Harvey EA, MacMillan JH, Goodman Y, Scott M, Balfe JW (1992) The peritoneal equilibration test in children. Kidney Int 42:102-105

7. Kohaut EC, Waldo FB, Benfield MR (1994) The effect of changes in dialysate volume on glucose and urea equilibration. Perit Dial Int 14:236-239

8. Warady BA, Alexander SR, Hossli S, Vonesh E, Geary D, Kohaut EC (1995) The relationship between intraperitoneal volume and solute transport in pediatric patients. J Am Soc Nephrol 5: 1935-1939

9. Verrina E, Amici G, Perfumo F, Trivelli A, Canepa A, Gusmano R (1998) The use of the PD Adequest mathematical model in pediatric patients on chronic peritoneal dialysis. Perit Dial Int $18: 322-328$

10. Warady BA, Alexander SR, Hossli S, Vonesh E, Geary D, Watkins S, Salusky IB, Kohaut EC (1996) Peritoneal membrane transport function in children receiving long-term dialysis. J Am Soc Nephrol 7:2385-2391

11. Twardowski ZJ, Nolph KD, Khanna R, Prowant BF, Ryan LP, Moore HL (1987) Peritoneal equilibration test. Perit Dial Bull 7:138-147

12. Schaefer F, Langebeck D, Heckert KH, Scharer K, Mehls O (1992) Evaluation of peritoneal solute transfer by the peritoneal equilibration test in children. Adv Perit Dial 8:410-415

13. National Kidney Foundation (2006) KDOQI clinical practice recommendations for 2006 updates: hemodialysis adequacy, peritoneal dialysis adequacy and vascular access. Am J Kidney Dis 48 [Suppl 1]:S1-S322

14. Schaefer F, Klaus G, Mehls O, Mid-European Pediatric Peritoneal Dialysis Study Group (1999) Peritoneal transport properties and dialysis dose affect growth and nutritional status in children on chronic peritoneal dialysis. J Am Soc Nephrol 10:1786-1792

15. Zialkowska H, Paczyk-Tomaszweska M, Debiaski A, Sawicki A, Roszkowska-Blaim M (2003) Bone metabolism and peritoneal membrane transport in children on chronic peritoneal dialysis. Perit Dial Int 23:487-492

16. Pride ET, Gustafson J, Graham A, Spoinhour L, Mauck V, Brown P, Burkart JM (2002) Comparison of a $2.5 \%$ and a $4.25 \%$ dextrose peritoneal equilibration test. Perit Dial Int 22:365-370

17. Warady BA, Jennings J (2007) The short PET in pediatrics. Perit Dial Int 27:441-445

18. Schaefer F (2007) The PET-iatrics of peritoneal solute transport: is short also good for the young ones? Perit Dial Int 27:413-414

19. Reddingius RE, Schröder CH, Willems JL, Lelivelt M, Kohler BEM, Krediet RT, Monnens LAH (1995) Measurement of peritoneal fluid handling in children on continuous ambulatory peritoneal dialysis using dextran 70 . Nephrol Dial Transplant 10:866-870

20. Bouts AHM, Davin JC, Groothoff JW, Ploos van Amstel S, Zweers MM, Krediet RT (2000) Standard peritoneal permeability analysis in children. J Am Soc Nephrol 11:943-950

21. Haraldsson B (1995) Assessing the individual peritoneal dialysis capacities of individual patients. A clinical tool based on the threepore model. Kidney Int 47:1187-1198

22. Schaefer F, Haraldsson B, Haas S, Simkova E, Feber J, Mehls O (1998) Estimation of peritoneal mass transport by three-pore model in children. Kidney Int 54:1372-1379

23. Fischbach M, Haraldsson B (2001) Dynamic changes of total pore area available for peritoneal exchange in children. J Am Soc Nephrol 12:1524-1529

24. Krediet RT, Lindholm B, Rippe B (2000) Pathophysiology of peritoneal membrane failure. Perit Dial Int 20 [Suppl 4]:S22S42

25. Williams JD, Craig KJ, Topley N, Williams GT (2003) Peritoneal dialysis: changes to the structure of the peritoneal membrane and potential for biocompatible solutions. Kidney Int 63 [Suppl 84]: S158-S161

26. Witoski J, Jorres A, Korybalska K, Ksiazek K, Wisniewska-Elnur J, Bender TO, Passlick-Deetjen J, Breborowicz A (2003) Glucose degradation products in peritoneal dialysis fluids: do they harm? Kidney Int 63 [Suppl 84]:S148-S151

27. Holmes CJ, Shockley TR (2000) Strategies to reduce glucose exposure in peritoneal dialysis. Perit Dial Int 20:S37-S41

28. Sitter T, Sauter M (2005) Impact of glucose in peritoneal dialysis: saint or sinner. Perit Dial Int 25:415-425

29. Williams JD, Topley N, Craig KJ, Mackenzie RK, Pischetsrieder M, Lage C, Passlick-Deetjen J (2004) The Euro-Balance Trial: the effect of a new biocompatible peritoneal dialysis fluid (Balance) on the peritoneal membrane. Kidney Int 66:408-418

30. Schmitt CP, von Heyl D, Rieger S, Arbeiter K, Bonzel KE, Fischbach M, Misselwitz J, Pieper AK, Schaefer F (2007) Reduced systemic advanced glycation end products in children receiving peritoneal dialysis with low glucose degradation product content. Nephrol Dial Transplant 22:2038-2044

31. Schröder CH (2001) The choice of dialysis solutions in pediatric chronic peritoneal dialysis: guidelines by an ad hoc European Committee. Perit Dial Int 21:568-574

32. Posthuma N, ter Wee PM, Donker AJM, Oe PL, Peers EM, Verbrugh HA (2000) Assessment of the effectiveness, safety, and biocompatibility of icodextrin in automated peritoneal dialysis. Perit Dial Int 20 [Suppl 2]:S106-S113 
33. De Boer AW, Schröder CH, Van Vliet R, Willems JL, Monnens LAH (2000) Clinical experience with icodextrin in children: ultrafiltration profiles and metabolism. Pediatr Nephrol 15:21-24

34. Verrina E, Amici G, Perfumo F, Trivelli A (2001) Evaluation of icodextrin absorption and ultrafiltration (UF) curve over a long day dwell in children on continuous cycling peritoneal dialysis. Perit Dial Int 21 [Suppl 1]:S93

35. van Hoeck KJ, Rusthoven E, Vermeylen L, Vandesompel A, Marescau B, Lilien M, Schroder CH (2003) Nutritional effects of increasing dialysis dose by adding an icodextrin daytime dwell to nocturnal intermittent peritoneal dialysis (NIPD) in children. Nephrol Dial Transplant 18:1383-1387

36. Rusthoven E, van der Vlugt ME, van Lingen-van Bueren LJ, van Schaijk TCJG, Willems HL, Monnens LAH, Schroeder CH (2005) Evaluation of intraperitoneal pressure and the effect of different osmotic agents on intraperitoneal pressure in children. Perit Dial Int 25:352-356

37. Rusthoven E, Krediet RT, Willems HL, Monnens LA, Schröder $\mathrm{CH}$ (2005) Sodium sieving in children. Perit Dial Int 25 [Suppl 3]: S141-S142

38. Martis L, Patel M, Giertych J, Mongoven J, Taminne M, Perrier MA, Mendoza O, Goud N, Costigan A, Denjoy N, Verger C, Owen WF Jr (2005) Aseptic peritonitis due to peptidoglycan contamination of pharmacopoeia standard dialysis solution. Lancet 365:588-594

39. Cooker LA, Holmes CJ, Hoff CM (2002) Biocompatibility of icodextrin. Kidney Int 62 [Suppl 81]:S34-S45

40. Gotloib L, Wajsbrot V, Shostak A (2005) Osmotic agents hamper mesothelial repopulation as seen in the doughnut in vivo model. Perit Dial Int 25 [Suppl 3]:S26-S30

41. Freida P, Galach M, Divino Filho JC, Werynski A, Lindholm B (2007) Combination of crystalloid (glucose) and colloid (icodextrin) osmotic agents markedly enhances peritoneal fluid and solute transport during the long PD dwell. Perit Dial Int 27:267-276

42. Jenkins SB, Wilkie ME (2003) An exploratory study of a novel peritoneal combination dialysate $(1.36 \%$ glucose $/ 7.5 \%$ icodextrin), demonstrating improved ultrafiltration compared to either component studied alone. Perit Dial Int 23:475-480

43. Canepa A, Perfumo F, Carrea A, Giallongo F, Verrina E, Cantalupi A, Gusmano R (1991) Long-term effect of amino-acid dialysis solution in children on continuous ambulatory peritoneal dialysis. Pediatr Nephrol 5:215-219

44. Canepa A, Carrea A, Menoni S, Verrina E, Trivelli A, Gusmano R, Perfumo F (2001) Acute effects of simultaneous intraperitoneal infusion of glucose and amino acids. Kidney Int 59:1967-1973

45. Canepa A, Verrina E, Perfumo F, Carrea A, Menoni S, Delucchi P, Gusmano R (1999) Value of intraperitoneal amino acids in children treated with chronic peritoneal dialysis. Perit Dial Int 19 [Suppl 2]:S435-S440

46. Garibotto G, Sofia A, Canepa A, Saffioti S, Sacco P, Sala MR, Dertenois L, Pastorino N, Deferrari G, Russo R (2001) Acute effects of peritoneal dialysis with dialysate containing dextrose or dextrose and amino acids on muscle protein turnover in patients on chronic renal failure. J Am Soc Nephrol 12:557-567

47. Olszowska A, Wanieski J, Werynski A, Anderstam B, Lindholm B, Wankowicz Z (2007) Peritoneal transport in peritoneal dialysis patients using glucose-based and amino acid-based solutions. Perit Dial Int 27:544-553

48. Witowski J, Jorres A (2005) Effects of peritoneal dialysis solutions on the peritoneal membrane: clinical consequences. Perit Dial Int 25 [Suppl 3]:S31-S33

49. Haas S, Schmitt CP, Arbeiter K, Bonzel KE, Fischbach M, John U, Pieper AK, Schaub TP, Passlick-Deetjen J, Mehls O, Schaefer F (2003) Improved acidosis correction and recovery of mesothelial cells mass with neutral-pH bicarbonate dialysis solution among children undergoing automated peritoneal dialysis. J Am Soc Nephrol 14:2632-2638

50. Fischbach M, Terzic J, Chauvé S, Laugel V, Muller A, Haraldsson B (2004) Effect of peritoneal dialysis fluid composition on peritoneal area available for exchange in children. Nephrol Dial Transplant 19:925-932

51. Schmitt CP, Haraldsson B, Doetschmann R, Zimmering $M$, Greiner C, Böswald M, Klaus G, Passlick-Deetjen J, Schaefer F (2002) Effects of pH-neutral, bicarbonate-buffered dialysis fluid on peritoneal transport in children. Kidney Int 61:1527-1536

52. Fischbach M, Dheu C, Seuge-Dargnies L, Delobbe JF (2007) Adequacy of peritoneal dialysis in children: consider the membrane for optimal prescription. Perit Dial Int 27 [Suppl 2]:S167S170

53. Fischbach M, Terzic J, Laugel V, Escande B, Dangelser C, Helmstetter A (2003) Measurement of hydrostatic intraperitoneal pressure: a useful tool for the improvement of dialysis dose prescription. Pediatr Nephrol 18:967-980

54. Fischbach M, Lahlou A, Eyer D, Desprez P, Geisert J (1996) Determination of individual ultrafiltration time (APEX) and purification phosphate time by peritoneal equilibration test: application to individual peritoneal dialysis modality prescription in children. Perit Dial Int 16 [Suppl 1]:S557-S560

55. Verrina E, Perfumo F (2004) Technical aspects of the peritoneal dialysis procedure. In: Warady BA, Schaefer FS, Fine RN, Alexander SR (eds) Pediatric dialysis. Kluwer Academic Publishers, Dordrecht, pp 113-134

56. Edefonti A, Consalvo G, Picca M, Giani M, Damiani B, Ghio L, Galato R (1995) Dialysis delivery in children in nightly intermittent and tidal peritoneal dialysis. Pediatr Nephrol 9:329-332

57. Hölltä T, Rönnholm K, Holmerg C (2000) Adequacy of dialysis with tidal and continuous cycling peritoneal dialysis in children. Nephrol Dial Transplant 15:1438-1442

58. Amici G (1999) Continuous tidal peritoneal dialysis. Prescription and power. In: Ronco C, Amici G, Feriani M, Virga G (eds) Automated peritoneal dialysis. Karger, Basel, pp 134-141

59. Brandes JC, Packard WJ, Watters SK, Fritsche C (1998) Optimization of dialysate flow and mass transfer during automated peritoneal dialysis. Am J Kidney Dis 25:603-610

60. Freida P, Issad B (1999) Continuous cyclic peritoneal dialysis prescription and power. In: Ronco C, Amici G, Feriani M, Virga G (eds) Automated peritoneal dialysis. Karger, Basel, pp 99-108

61. Vonesh EF (1999) Membrane transport models and computerized kinetic modeling applied to automated peritoneal dialysis. In: Ronco C, Amici G, Feriani M, Virga G (eds) Automated peritoneal dialysis. Karger, Basel, pp 15-34

62. Warady BA, Watkins SL, Fivush BA, Andreoli SP, Salusky I, Kohaut EC, Vonesh EF (2001) Validation of PD Adequest 2.0 for pediatric dialysis patients. Pediatr Nephrol 16:205-211

63. Ho-dac-Pannekeet MM, Atasever B, Strujik DG, Krediet RT (1997) Analysis of ultrafiltration failure in peritoneal dialysis patients by means of standard peritoneal permeability analysis. Perit Dial Int 17:144-150

64. Mujais S, Nolph K, Blake P, Burkart J, Coles G, Kawaguchi Y, Kawanishi H, Korbet S, Krediet R, Lindholm B, Oreopoulus D, Rippe B, Selgas R (2000) Evaluation and management of ultrafiltration problems in peritoneal dialysis. Perit Dial Int 20 [Suppl 4]:S5-S21

65. Kiernan L, Kliger A, Gorban-Brennan N, Juergensen P, Tesin D, Vonesh E, Finkelstein F (1995) Comparison of CAPD related infections with different, Y-tubing"exchange systems. J Am Soc Nephrol 5:1835-1838

66. Monteon F, Corra-Rotter P, Paniagua R, Amato D, Hurtado ME, Medina JL, Salcedo RM, Garcia E, Matos M, Kaji J, Vazquez R, Ramos A, Schettino MA, Moran J (1998) Prevention of peritonitis 
with disconnect systems in CAPD. The Mexican Nephrology Collaborative Study Group. Kidney Int 54:2123-2128

67. Warady BA, Schaefer FS (2004) Peritonitis. In: Warady BA, Schaefer FS, Fine RN, Alexander SR (eds) Pediatric dialysis. Kluwer Academic Publishers, Dordrecht, pp 393-413

68. Dell'Aquila R, Rodighiero MP, Spano M, Di Loreto P, Ocampo Kohn C, Cruz D, Polanco N, Kuang D, Corradi V, De Cal M, Ronco C (2007) Advances in the technology of automated, tidal and continuous flow peritoneal dialysis. Perit Dial Int 27 [Suppl 2]:S130-S137

69. Edefonti A, Boccola S, Picca M, Paglialonga F, Ardissino G, Marra G, Ghio L, Parisotto MT (2003) Treatment data during pediatric home peritoneal dialysis. Pediatr Nephrol 18:560564

70. Gallar P, Vigil A, Rodriguez I, Ortega O, Guterriez M, Hurtado J, Oliet A, Ortiz M, Mon C, Herrero JC, Lentisco C (2007) Twoyear experience with telemedicine in the follow-up of patients in home peritoneal dialysis. J Telemed Telecare 13:288-292

71. Nakamoto H (2007) Telemedicine system for patients on continuous ambulatory peritoneal dialysis. Perit Dial Int 27 [Suppl 2]:S21-S26

72. Cargill A, Watson AR (2003) Telecare support for patients undergoing chronic peritoneal dialysis. Perit Dial Int 23:91-94

73. Brunkhorst R, Fromm S, Wrenger E, Berke A, Petersen R, Riede G, Westphale J, Zamore E, Ledebo I (1998) Automated peritoneal dialysis with "online"-prepared bicarbonate-buffered dialysate:
Technique and first clinical experiences. Nephrol Dial Transplant 13:3189-3192

74. Ronco C, Amerling R (2006) Continuous flow peritoneal dialysis: current state-of-the-art and obstacles to further development. Contrib Nephrol 150:310-320

75. Woodrow G (2007) Methodology of assessment of fluid status and ultrafiltration problems. Perit Dial Int 27 [Suppl 2]:S143-S147

76. Fischbach M, Terzic J, Menouer S, Soulami K, Dangelser C, Helmstetter A, Gehant F (2001) Effects of automated peritoneal dialysis on residual daily urinary volume in children. Adv Perit Dial 17:269-273

77. Morgenstern BZ, Wuhl E, Nair KS, Warady BA, Schaefer F (2006) Anthropometric prediction of total body water in children who are on pediatric peritoneal dialysis. J Am Soc Nephrol $17: 285-293$

\section{Answers}

1. c
2. b
3. c
4. d
5. b 